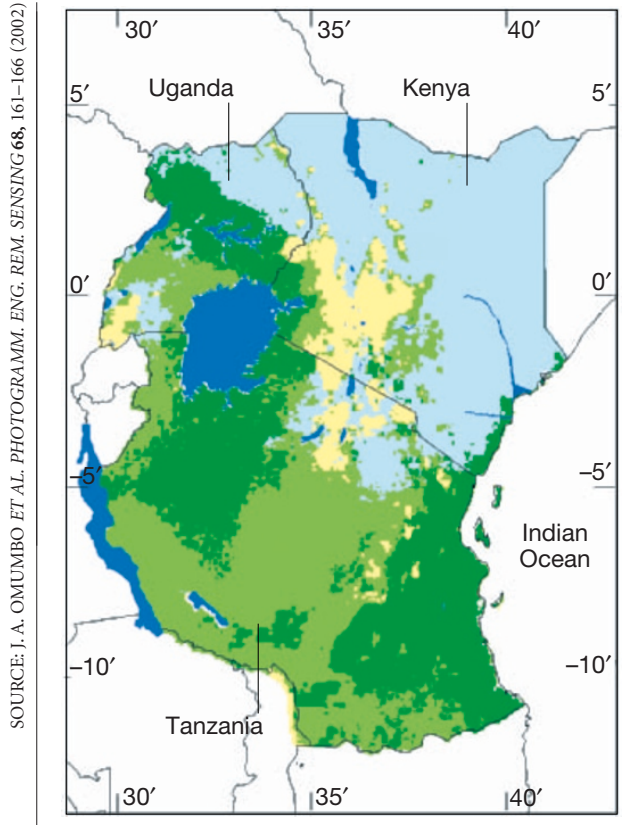

Satellite sensor model of malaria transmission in East Africa

Malaria free

Malaria near water

Moderate malaria transmission

Intense malaria transmission given that the relevant questions are buried in a national-health survey questionnaire the size of the Oxford English Dictionary.

Similarly, RBM's target of providing bednets to $60 \%$ of children is not framed scientifically to ensure that these reach the most vulnerable. The distribution often correlates more closely with wealth than areas of high malaria risk?

In 2001, the UK government granted one non-governmental organization US $\$ 22$ million to market nets in Kenya. But it focused on urban rather than rural areas. The outcome: a mere $1.5 \%$ increase in children protected - hardly a stunning success.

The best way to measure the impact of interventions would be to use rigorous, longitudinal demographic and epidemiological studies, such as those provided by the INDEPTH network of sentinel sites (www.INDEPTH-network.org). But such sites are few - there are only 11 in Africa. We urgently need a properly funded, sciencebased strategy to evaluate the use of both existing and future malaria control tools.

Clinical trials of new vaccines and drugs for malaria, such as those planned by the recently launched European and Developing Countries Clinical Trials Partnership, will eventually require sites where operational effectiveness can be measured.

More money won't be enough. Donors, governments and international initiatives must take on board the concerns of scientists in the field, and back political goals with hard science. Without a greater appreciation of the importance of creditable baseline data, and the need for adequate funding and resources to gather such data, in a decade or so we will not be celebrating the rolling back of malaria -we will be scratching our heads wondering whether we made any difference at all.

Robert W. Snow is at the Kenya Medical Research Institute/Wellcome Trust Collaborative Programme in Nairobi, Kenya.

1. Snow, R. W., Trape, J. F. \& Marsh, K. Trends Parasitol. 17, 593-597 (2001)

2. The Abuja Declaration on Roll Back Malaria in Africa (2000); available at www.usaid.gov/our_work/global_health/id/ malaria/publications/docs/abuja.pdf.

3. United Nations Development Programme Human Development Report 2003. Millennium Development Goals: A Compact Among Nations to End Human Poverty (Oxford Univ. Press, New York, 2003); available at hdr.undp.org/reports/global/2003.

4. Rogers, D. J., Randolph, S. E., Snow, R. W. \& Hay, S. I. Nature 415, 710-715 (2002).

5. Hay, S. I., Guerra, C. A., Tatem, A. J., Noor, A. M. \& Snow, R. W. Lancet Infect. Dis. 4, 327-336 (2004).

6. Snow, R.W., Craig, M. H., Newton, C. R. J. C. \& Steketee, R. W. The Public Health Burden of Plasmodium falciparum Malaria in Africa: Deriving the Numbers DCPP Working Paper 11 (DCPP Bethesda, Maryland, 2003); available at www.fic.nih.gov/dcpp/ wps/wp11.pdf.

7. Monasch, R. et al. Am. J. Trop. Med. Hyg. (in the press).

\section{Struggling to make an impact}

Hampered by bureaucracy, politics and ineffectual policies, critics claim that the international Roll Back Malaria (RBM) partnership is failing, and is a long way off its goal of halving malaria deaths by 2010. Few of the 44 African countries that signed up to its main goals, including providing immediate access to treatment for $60 \%$ of patients by 2005 , have followed up with increased resources.

Allan Schapira, RBM coordinator at the World Health Organization (WHO), disputes that the programme is off-course, arguing that it will take years for the impact of current initiatives to become apparent. "There's no basis for the contention that deaths from malaria have gone up," he says, adding that tracking trends in malaria-specific deaths over short periods is difficult. What is clear, however, is that no data show substantial drops in deaths in sub-Saharan Africa, where most cases occur.

RBM was launched in 1998 by the WHO, the World Bank, the United Nations Development
Programme and UNICEF, and is now supported by 90 countries. It has raised the disease's international profile, says Roger Bate of the American Enterprise Institute for Public Policy Research, a Washington-based think-tank. "Unfortunately, I think that's kind of where the good news ends," he says. "If RBM were a government, it would be voted out of office."

In 2002, an external evaluation panel concluded that RBM was failing at regional and national levels, and was too isolated from local health policies (see Nature 419, 422; 2002). It also found the World Bank's commitment to be ambivalent. "We are committed to doing a lot more, to doing much better," says Olusoji Adeyi, communicable-diseases coordinator at the bank.

RBM has since been reorganized to make it more accountable to malarial countries, and to have a tighter focus on fewer countries. Mark Young, UNICEF's senior health adviser for RBM, points to 'basket funding', where money is pooled nationally and health ministries make spending decisions.

But critics also complain about the programme's inertia in replacing obsolete drugs with more effective, but costlier, artemisininbased drugs (see Nature 429, 588; 2004). In addition, they question its focus on mosquito nets soaked in insecticides to the exclusion of indoor spraying with DDT and other insecticides.

RBM claims that it promotes DDT wherever appropriate, but argues that nets are safer and more effective. Spraying is difficult to push through politically, says Schapira, with pressure from government and other donors. "We have had very, very strong lobbying over DDT," he says. "We have had to give up."

The biggest issue, says Schapira, is money. Most new funding for African countries is coming from the Global Fund to Fight AIDS, Tuberculosis and Malaria, although it is far short of the billions needed. "We have the tools and the strategies, but without more money it will be a disaster." Apoorva Mandavilli is news editor of Nature Medicine. 